Gazi University, etugcular@yahoo.com, Ankara-Turkey

http://dx.doi.org/10.12739/NWSA.2017.12.2.D0196

GELENEKSEL TÜRK HALK MÜZİĞİNDE KARMA ÖLÇÜLERİN ANALİTIKK İNCELENMESİ

öz

Geleneksel Türk halk müziği, ritim ve makam bakımından oldukça zengin bir yapıya sahiptir. Yapılan literatür taramasında Geleneksel Türk halk müziğinin temel konularından biri olan ölçülerin yeteri kadar incelenmemiş olduğu, özellikle karma ölçülere ilişkin açıklamaların literatürde bazı belirsizlikler içerdiği gözlenmiştir. Bu araştırmada TRT Türk halk müziği repertuvarında yer alan 11/8'lik, 12/8'lik, 13/8'lik, 14/8'lik, 15/8'lik, 16/8'lik, 17/8'lik, 18/8'lik, 19/8'lik, 20/8'lik, 21/8'lik, 23/8'lik, 25/8'lik, 27/8'lik,30/8'lik ölçü olarak notaya alınmış, karma ölçülü türküler vuruş, dizilim ve ölçü karmaları belirtilerek tablolaştırılmıştır. Bu tablolar, TRT repertuvarındaki yaklaşık beş bin türkü içerisinden seçilen örneklerle desteklenmiş ve açıklanmıştır. Tarama modelinde ve betimsel bir yaklaşımla gerçekleştirilen bu araştırmada veriler, kaynak taraması yapılarak ve analitik bir bakış açısıyla ortaya konmuştur. Araştırma sonucunda, incelenen karma ölçülü türkülerin iki ya da daha fazla ölçüden oluştuğu ve karma ölçülerin dizilimlerinin ise her türküde farklılıklar gösterdiği belirlenmiştir.

Anahtar Kelimeler: Halk Müziği, Türkü, Usul, Karma Ölçü, Vuruş, Ritim ve Dizilim

\title{
ANALYTICAL INVESTIGATION OF MIXED MEASUREMENTS IN TRADITIONAL TURKISH FOLK MUSIC
}

\section{ABSTRACT}

Traditional Turkish Folk Music has a very rich rhythmic and maqamic structure. After review of the literature, we observed that the mixed measure concept, one of the basic issues in Turkish Folk Music, was not analyzed sufficiently and there were unclear classifications about it. With this respect, in this study, the folk songs with mixed measures in $11 / 8,12 / 8,13 / 8,14 / 8,15 / 8,16 / 8,17 /$ $8 / 8,18 / 8,19 / 8,20 / 8,21 / 8,23 / 8,25 / 8,27 / 8,30 / 8$ meters were analyzed in terms of beat, sequencing and mixture, and the data was shown in tables. Next, this tables were explained through the prominent examples selected from about 5000 songs in the Turkish Radio and Television folk song repertoire. In the study, descriptive research design and the data was gathered through literatüre review. The result of the study showed that the folk songs with mixed measures mostly consisted of two or more measures and the metric sequence were unique in each folk song.

Keywords: Folk Music, Folk Song, Mixed Measure, Beat, Rhythm and Metric Sequence 


\section{GİRIŞ (INTRODUCTION)}

Geleneksel Türk sanat müziğinde ölçü kavramı genellikle "usul" kelimesiyle tanımlanmaktadır (Şenol, 2016:8). Geleneksel Türk halk müziğinde ise usul ve ölçü kelimeleri aynı anlamda kullanılmaktadır. Muzaffer Sarısözen konuyu usul olarak ele alıp "Türk Halk Müziği Usulleri" kitabında "Ana Usul, Birleşik Usul ve "Karma Usul" olarak üç guruba ayırmıştır. Sarısözen'in tanımlamasında, 10/8'lik ve daha büyük ölçüler karma usuller içerisinde yer almaktadır. Karma ölçüleri; "birleşiklerin veya ana usullerle birleşiklerin bir araya gelmesiyle teşekkül eder" diye tanımlamaktadır (Sarısözen, 1962:96). Bu tanım o dönem için karma ölçülerle ilgili yapılmış en açık tanımlamadır. Ancak Muzaffer Sarısözen'in yaptığı bu tanımlamaya 10/8'lik ölçü biçimi uymamaktadır. 10/8'lik ölçünün kendine özgü dizilim biçimleri bulunmakta ve farklı ölçülerin bir araya gelmesinden oluşmamaktadır. Bu nedenle, $3+2+2+3,3+3+2+2, \quad 2+3+3+2$ şeklinde üç biçimi (düzüm, dizilim) olan 10/8'lik ölçüyü aksak ölçü olarak sınıflamak, 11/8'lik ve daha büyük ölçüleri karma ölçü olarak tanımlamak daha uygun olacaktır.

Bir türkünün ya da bir ezginin ölçüsünü belirleyebilmek için, o ölçünün vuruş, zaman ve sayısını belirlemek gerekmektedir. Örneğin 2/4, 5/8 ve 6/8'lik ölçülerin üçü de iki vuruşludur. Ancak 2/4'lük ölçü iki zamanlı basit ölçü, 5/8'lik beş zamanlı aksak, 6/8'lik ölçü ise altı zamanlı bileşik ölçü gurubundandır. Bu bağlamda Türk halk müziği repertuarında yer alan türkülerde kullanılan ölçüleri, vuruş, zaman ve tür gurubunu temel alınarak "basit ölçüler", "bileşik ölçüler", "aksak ölçüler" ve "karma ölçüler" olarak sınıflamak daha uygun olacağı düşünülmüştür. Bu sınıflama batı müziği teorisinde de aşağıda verilen adlandırmayla benzer şekilde yer almaktadır.

- Basit ölçüler "simple meters" (1997:237): Birim vuruşları "dörtlük" nota değeri olan 2/4, 3/4, 4/4, 5/4, 6/4, 7/4, 8/4, $9 / 4$ ölçülerdir.

- Bileşik Ölçüler "compound meters"(1997:237):Birim vuruşları "noktalı dörtlük" nota değeri olan 6/8, 9/8, 12/8, 15/8, $18 / 8$ 'lik ölçülerdir.

- Aksak Ölçüler (asymmetric meters) "asimetrik ölçüler" (2007:50): Birim vuruşları hem dörtlük hem de notalı dörtlük olan 5/8, 7/8, $8 / 8,9 / 8,10 / 8^{\prime} l i k$ ölçülerdir.

- Karma ölçüler:11/8 ve üzeri ölçülerdir. Batı müziği terminolojisinde "mixed meters" ya da "changing meter" (Ashish, 2005) terimleri kullanılmaktadır. Burada kastedilen Türk Halk Müziğinde, bir ölçü içerisinde kullanılan karma ölçüler değil, bir eser içerisinde art arda farklı ölçülerin getirilmesidir.

Yapılan literatür taraması sonucu elde edilen araştırmalarda, karma ölçülerle ilgili olarak benzer tanımlar yapıldığı görülmüştür. Mansur Kaymak (1982:178) "Türk Halk Müziği ve Oyunları" dergisinde Zeki Büyük Yıldız (2009:159) "Türk Halk Müziği" Kitabında, Atınç Emnalar (1998:133) "Türk Halk Müziği ve Nazariyatı" adlı kitabında karma usulleri: On vuruşlular: 10/4, 10/8, 10/16, (3+2+2+3, 2+3+3+2), On bir vuruşlular:11/8 $(7 / 8+4 / 8,5 / 8+6 / 8)$, On iki vuruşlular: $12 / 8$ $(5 / 8+7 / 82+3+2+3+2)$, On beş vuruşlular: 15/4, 15/8 (7/8+8/8, 8/8+7/8), On altı vuruşlular: $16 / 8(9 / 8+8 / 8)$, On sekiz vuruşlular:18/8 (12/8+6/8), Yirmi vuruşlular. 20/8 (6/8+7/8++7/8), Yirmi bir vuruşlular: $21 / 8(12 / 8+9 / 8)$ olarak belirtmişlerdir. Talip Özkan (1989) "Türk Halk Müziğinin Makam ve Ritim Analizi" adlı Doktora Tezinde karma ölçüleri: 10/8, 11/8, 12/8, 15/8, 16/8, 18/8, 20/8, 21/8, 25/8, 28/8 olarak belirtmiştir. Cihangir Terzi (1992:133) "Sanatta Yeterlik" tezinde karma ölçüleri 11/8, 12/8, 13/8, 14/8, 15/8, 17/8 ve 18/8'lik ölçüler olarak ele almıştır. Atınç Emnalar (1998:139) "Türk Halk 
Müziği ve Nazariyatı" adlı kitabında karma usuller olarak 10/8, 11/8, 12/8, 15/8, 15/4, 16/8, 20/8, 21/8'lik ölçüleri sıralamıştır. Adı geçen Kaynaklarda karma ölçülerin 10/8'lik ya da 11/8'lik ölçü ve üzeri ölçüler olarak kabul edildiği, ancak bazı ölçülerin bu kapsam içerisine alınmadığı görülmektedir.

Bu araştırmada karma ölçüler, en az iki ölçünün bir araya gelmesiyle oluşan ve dizilim biçimleri sabit olamayan ölçüler" olarak tanımlanmaktadır. Bu tanıma uygun olarak 11/8'lik ve üzeri ölçüler karma ölçü olarak belirlenmiş ve TRT repertuvarında yer alan 16 karma ölçü incelenmiştir. Bu türküler 11/8, 12/8, 13/8, 14/8, 15/8, 16/8, $17 / 8,18 / 8,19 / 8,20 / 8,21 / 8,23 / 8,25,27 / 8,28 / 8$ ve 30/8'lik olarak notaya alınmış türkülerdir. İnceleme sonucu bu türkülerin iki ya da daha fazla ölçüden oluştuğu, vuruş ve dizilimlerin düzenli olmadığı, çoğunlukla her türküde farklı olduğu belirlenmiştir. Örnek olarak 8/8'lik ölçü 3+2+3, 3+3+2, 2+3+3 biçimindeki sabit dizilimlerden oluşmaktadır. Buna karşılık 11/8'lik ölçüyle notaya alınmış beş türkü incelendiğinde $2+2+3+2+2, \quad 3+2+2+2+3, \quad 3+2+3+3,2+3+3+3, \quad 3+3+3+2$ gibi beş farklı diziliminin olduğu görülmektedir. Yapılan araştırmada 11/8'lik olarak notaya alınmış türkülerin bazılarının dört, bazılarının ise beş vuruşlu olduğu belirlenmiştir. Bu durum, karma ölçülerde sadece dizilimlerin değil, vuruş sayılarının da sabit olmadığını göstermektedir.

Araştırmada, karma ölçüyle yazılmış türkülerin farklı dizilimlerden oluşan örnekleri sergilenmiştir. Tablolar; "ölçü, dizilim, vuruş, ölçü karması ve türkünün adından" oluşmaktadır. Ölçü̈; hangi karma ölçü olduğunu, dizilim; ölçü içerisinde kullanılan ikişerli (.J) ve üçerli (...) sürelerin sıralanış şeklini, vuruş, ölçü içerisinde yer alan ikişerli ve üçerli dizilimlerin sayısını, ölçü karması ise karma ölçünün hangi (aksak, basit, bileşik) ölçü gurubundan oluştuğunu göstermektedir. Ölçü karması motif yapısı söz ve ritim yapısı esas alınarak belirlenmiştir.

Verilen nota örneklerinde, türkünün repertuardaki tam adı, yöresi ve farklı dizilimlerden oluşan biçimlerine yer verilmiştir. Örneğin, aşağıda notası görülen Malatya yöresine ait 17/8'lik "Sabah Olur Oğlan Gider İşine" adlı türkünün nota ile 8 8.................. dizilim biçimi, rakamla $2+2+2+3+3+2+3$ ölçü dizilimi şeklinde gösterilmiştir. Ayrıca abartılı olduğu düşünülen bazı ölçülerde uygun ölçülendirme önerileri gösterilmiştir.

\begin{tabular}{|c|c|c|c|c|}
\hline Ölçü & Dizilim & Vuruş & Ölçü Karması & Türkünün Adı \\
\hline $17 / 8$ & $2+2+2+3+3+2+3$ & 7 & $9 / 8+8 / 8$ & Sabah Olur Oğlan. . \\
\hline
\end{tabular}

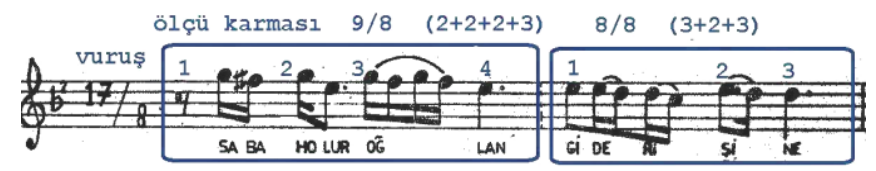

Geleneksel Türk halk müziği ritim ve makam bakımından oldukça zengin bir yapıya sahiptir. Bu çalışmanın temel amacı, ölçü kavramında yeteri kadar incelenmeyen karma ölçüleri incelenmek ve belirsiz olan sınıflamaları belirlemektir.

\section{2. ÇALIŞMANIN ÖNEMI (RESEARCH SIGNIFICANCE)}

Bu çalışma, müzik öğrencileri, müzik eğitimcileri ve geleneksel müzik alanında çalışanlar ve bestecilerin karma ölçülerle ilgili bilgi dağarcıklarının arttırılması ve bakış açılarının geliştirmesine katkıda bulunması bakımından önemlidir. 


\section{YÖNTEM (METHOD)}

Bu araştırma, TRT repertuarında yer alan 4989 türküden seçilmiş karma ölçüyle notaya alınan türküleri, dizilim, vuruş ve ölçü karması yönünden inceleyen betimsel bir çalışmadır. Yapılan araştırmada, karma ölçü ve diğer ölçülerle birlikte yazılmış türkülerin sayısal tablosu EK-1'de, incelenen karma ölçülü türküler EK-2'de verilmiştir.

\section{BULGULAR VE TARTIŞMALAR (FINDING AND DISCUSSION)}

Yapılan araştırmada, TRT repertuarında notaya alınmış türkülerde $11 / 8,12 / 8,13 / 8,14 / 8,15 / 8,16 / 8,17 / 8,18 / 8,19 / 8,20 / 8,21 / 8$ 23/8, 25, 27/8, 28/8 ve 30/8'lik 16 karma ölçü belirlenmiştir. Bu ölçülerin tamamı "sözlü ezgiler" bölümünde yer almaktadır. Repertuvarın "Sözsüz ezgiler" ya da "oyun havaları" olarak adlandırılan kısmında ise karma ölçüyle notaya alınmış ezgi bulunmamaktadır. Cihangir Terzi(1992), bu durumu "Türkü yakma geleneğinde daha çok yörelerde ritim ve ezgi kalıpları üzerine söz uygulanarak türkü üretilir. Bazen söz gurupları müzikal yapıyı esnemeye zorlayarak geniş usul yapıları ortaya çıkarırlar" diye açıklamaktadır.

\subsection{1/8' Lik Ölçü (11/8 Measure)}

11/8'lik ölçü iki farklı ölçünün bir araya gelmesiyle oluşan, dört ya da de beş vuruşlu ölçüdür. Genellikle 5/8, 6/8, 2/4 ya da 7/8'lik ölçülerin bir araya gelmesiyle oluştuğu görülmektedir. TRT repertuarında, 11/8'lik ölçüyle notaya alınmış beş türkü, diğer ölçülerle (örn. 11/8+4/4) birlikte yazılmış sekiz türkü bulunmaktadır. $\mathrm{Bu}$ türkülerin ikişerli ve üçerli dizilimleri incelendiğinde genellikle $2+3+2+2+2$ dizilimiyle oluştuğu görülmektedir. Bu dizilimler dışında $3+2+3+2+1+1+1, \quad 3+2+3+3, \quad 2+2+3+3$ ve $3+3+3+2$ biçimlerine de rastlanmaktadır.

Tablo 1. 11/8'lik karma ölçü yapıları

(Table 1. $11 / 8$ mixed measure forms)

\begin{tabular}{|c|c|c|c|c|}
\hline Ölçü & Dizilim & Vuruş & Ölçü Karması & Türkünün Adı \\
\hline \multirow{5}{*}{$11 / 8$} & $2+2+3+2+2$ & 5 & $7 / 8+2 / 4$ & Başı Pare Pare \\
\cline { 2 - 5 } & $3+2+1+1+1$ & 5 & $5 / 8+3 / 4$ & Gül Kuruttum \\
\cline { 2 - 5 } & $3+2+3+3$ & 4 & $5 / 8+6 / 8$ & Havada Kar Sesi Var \\
\cline { 2 - 5 } & $2+3+3+3$ & 4 & $5 / 8+6 / 8$ & Top Yatağın Önü \\
\cline { 2 - 5 } & $3+3+3+2$ & 4 & $6 / 8+5 / 8$ & Güzel Yanlış Gidiyor \\
\hline
\end{tabular}

Tablo 1'de görüldüğü gibi 11/8'lik ölçünün beş farklı dizilimi kullanılmıştır. Bunlar $2+2+3+2+2, \quad 3+2+1+1+1, \quad 3+2+3+3, \quad 2+3+3+3$ ve 3+3+3+2 dizilimlerinden oluşmaktadır. 11/8'lik ölçünün hem dört, hem de beş vuruşlu olarak kullanıldığı görülmektedir. Dizilimler 7/8+2/4, $5 / 8+3 / 4,5 / 8+6 / 8,6 / 8+5 / 8$ ölçü karmasından oluşmaktadır. Yukarıda tabloda verilen türkü örnekleri aşağıda verilmiştir.

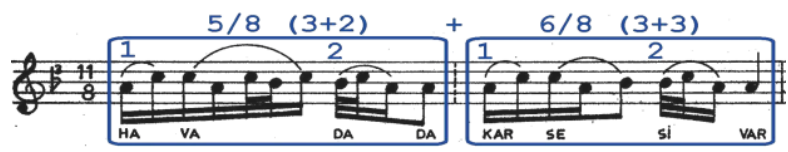

Örnek 1a. Havada kar sesi var (Kahramanmaraş)

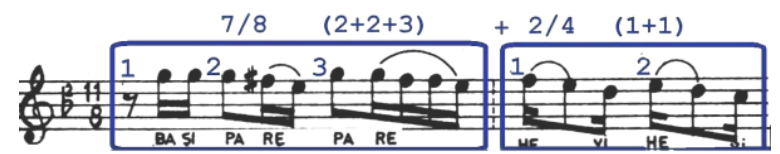

Örnek 1b. Başı pare pare dumanlı dağlar (Erzincan) 


\subsection{2/8' Lik Ölçü (12/8 Measure)}

12/8'lik ölçünün hem bileşik hem de karma ölçü olarak kullanıldığı belirlenmiştir. Ancak, karma ölçü olarak az sayıda örneğe rastlanılmıştır. TRT repertuarında, bu ölçüyle notaya alınmış iki türkü bulunmaktadır.

Tablo 2. 12/8'lik karma ölçü yapıları

(Table 2. $12 / 8$ mixed measure forms)

\begin{tabular}{|c|c|c|c|c|}
\hline Ölçü & Dizilim & Vuruş & Ölçü Karması & Türkünün Adı \\
\hline \multirow{2}{*}{$12 / 8$} & $2+3+3+2+2$ & 5 & $8 / 8+2 / 4$ & İndim Koç Babayı \\
\cline { 2 - 5 } & $3+2+2+2+3$ & 5 & $5 / 8+7 / 8$ & Tutam Yar Elinden \\
\hline
\end{tabular}

Tablo 2'de görüldüğü gibi bu türküler $2+3+3+2+2$ ve $3+2+2+2+3$ dizilimlerinden oluşmaktadır. 12/8'lik ölçünün beş vuruşlu olarak kullanıldığı ve dizilimlerinin $8 / 8+2 / 4$ ve 5/8+7/8'lik ölçü karmasından oluştuğu görülmektedir.

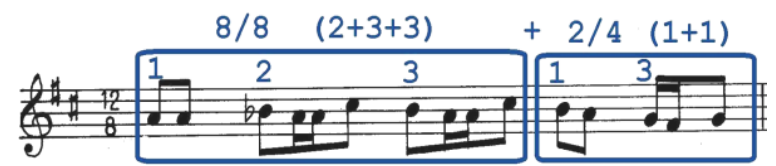

Örnek 2a. İndim koç babayı tavaf eyledim (Ankara)

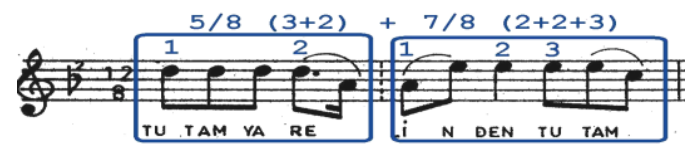

Örnek 2b. Tutam yar elinden (Erzurum)

\subsection{3/8' Lik ölçü (13/8 Measure)}

TRT repertuarında, $13 / 8$ ölçüyle notaya alınmış dört türkü, diğer ölçülerle birlikte yazılmış altı türkü bulunmaktadır.

Tablo 3. 13/8'lik karma ölçü yapıları

(Table 3. $13 / 8$ mixed measure forms)

\begin{tabular}{|c|c|c|c|c|}
\hline Ölçü & Dizilim & Vuruş & Ölçü Karması & Türkünün Adı \\
\hline \multirow{4}{*}{$13 / 8$} & $3+3+2+2+3$ & 5 & $6 / 8+7 / 8$ & Selam Olsun Size \\
\cline { 2 - 5 } & $2+3+3+2+3$ & 5 & $8 / 8+5 / 8$ & Yeni Kapının Gelini \\
\cline { 2 - 5 } & $2+3+1+1+1+1$ & 6 & $5 / 8+4 / 4$ & Gelin Çıkarma Havası \\
\cline { 2 - 5 } & $2+2+2+2+3+2$ & 6 & $4 / 4+5 / 8$ & \multicolumn{2}{|c|}{ Ahmedim } \\
\hline
\end{tabular}

Tablo 3'de görüldüğü gibi 13/8'lik ölçüyle yazılmış türkülerde dört farklı dizilim kullanılmıştır. Bunlar $3+3+2+2+3,2+3+3+2+3$ $2+3+2+2+2+2$ ve $2+2+2+2+3+2$ dizilimleridir. 13/8'lik ölçünün hem beş, hem de altı vuruşlu olduğu görülmektedir. Dizilimler $6 / 8+7 / 8,5 / 8+4 / 4$, $8 / 8+5 / 8$ ve 4/4+5/8 ölçü karmasından oluşmaktadır. Karma ölçülerde dizilim bazen aynı türkü içerisinde değişmektedir. Örneğin: "Gelin Çıkarma Havası" (Akbakırlar, Rumeli) türküsü 2+3+2+2+2+2 olan dizilimi sonraki ölçülerde $2+2+3+1+1+1$ olarak değişiklik göstermiştir.

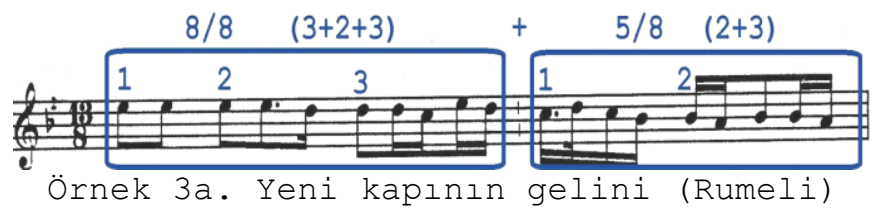




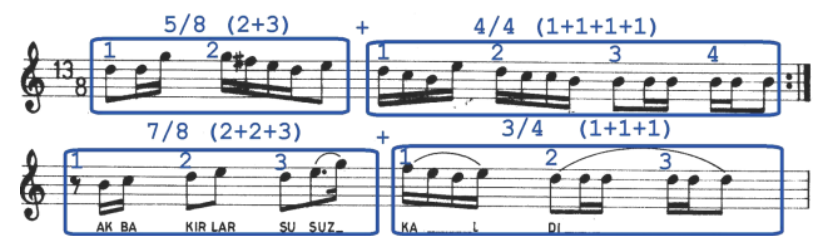

Örnek 3b. Gelin çıkarma havası-Akbakırlar-(Rumeli)

\subsection{4/8' Lik Ölçü (14/8 Measure)}

TRT repertuvarında, 14/8'lik ölçüyle notaya alınmış ve diğer ölçülerle birlikte yazılmış üçer türkü bulunmaktadır. Tablo 4'de türkülerin $3+2+3+3+3,3+2+2+2+3+2,3+3+3+2+3,2+2+2+3+2+3$ ve $3+3+3+3+2$ dizilimlerinden oluştuğu görülmektedir. Bu türkülerde 14/8'lik ölçünün beş ve altı vuruşlu olarak kullanıldığı ve dizilimlerinin $8 / 8+6 / 8$, $7 / 8+8 / 8,6 / 8+8 / 8,9 / 8+5 / 8$ ve $9 / 8+5 / 8$ ölçü karmasından oluştuğu görülmektedir. Bu 14/8'lik ölçüyle notaya alınmış türküler içerisinde "Bir Yar Getirmişim" türküsü iki 7/8'lik ölçünün farklı dizilimlerinin bir araya gelmesiyle ilginç bir yapı oluşturmaktadır.

Tablo 4. 14/8'lik karma ölçü yapıları

(Table 4.14/8 mixed measure forms)

\begin{tabular}{|c|c|c|c|c|}
\hline Ölçü & Dizilim & Vuruş & Ölçü Karması & Türkünün Adı \\
\hline \multirow{4}{*}{$14 / 8$} & $3+2+3+3+3$ & 5 & $8 / 8+6 / 8$ & Fincanın İçi Fil Olur \\
\cline { 2 - 5 } & $3+3+3+3+2$ & 5 & $9 / 8+5 / 8$ & Çattılar Ocak Daşını \\
\cline { 2 - 5 } & $3+3+3+2+3$ & 5 & $6 / 8+8 / 8$ & İndim Yârin Bahçesine \\
\cline { 2 - 5 } & $2+2+2+3+2+3$ & 6 & $9 / 8+5 / 8$ & Yollar Seni Gide Gide \\
\cline { 2 - 5 } & $3+2+2+2+3+2$ & 6 & $7 / 8+7 / 8$ & Bir Yar Getirmişim \\
\hline
\end{tabular}

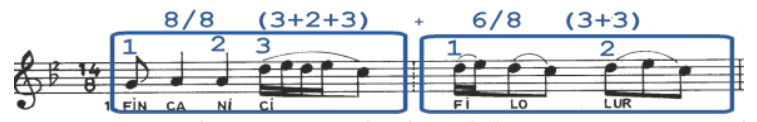

Örnek 4a. Fincanın içi fiğ olur (Artvin)

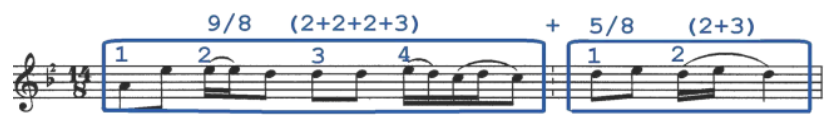

Örnek 4b. Yollar seni gide gide usandım (Malatya)

\subsection{5/8' Lik Ölçü (15/8 Measure)}

15/8'lik ölçü hem bileşik hem de karma ölçü sınıflaması içerisinde yer almaktadır. Ancak bileşik 15/8'lik ölçüyle notaya alınmış türküye rastlanılmamıştır. TRT repertuarında karma ölçü olarak notaya alınmış beş türkü ve diğer ölçülerle birlikte yazılmış iki türkü bulunmaktadır. Bu türkülerden "Zeynep Bu Güzellik Var mı Soyunda" türküsü dahil üç türkü aynı dizilim biçimine sahip olduğu belirlenmiştir.

Tablo 5. 15/8'lik karma ölçü yapıları

(Table 5. $15 / 8$ mixed measure forms)

\begin{tabular}{|c|c|c|c|c|}
\hline Ölçü & Dizilim & Vuruş & Ölçü Karması & Türkünün Adı \\
\hline \multirow{4}{*}{$15 / 8$} & $2+3+3+2+2+3$ & 6 & $8 / 8+7 / 8$ & Zeynep Bu Güzellik \\
\cline { 2 - 5 } & $2+2+3+3+2+3$ & 6 & $7 / 8+8 / 8$ & Uyan Gözlerine \\
\cline { 2 - 5 } & $2+3+3+2+2+3$ & 6 & $8 / 8+7 / 8$ & Evleri Fadimelim \\
\cline { 2 - 5 } & $3+2+2+3+2+3$ & 6 & $7 / 8+8 / 8$ & Yeşil İpek Bükerim \\
\cline { 2 - 5 } & $2+2+2+2+3+2+2$ & 7 & $4 / 4+7 / 8$ & Gelin Oldum \\
\hline
\end{tabular}




\begin{abstract}
Tablo 5'de görüldüğü gibi, "Zeynep Bu Güzellik Var mı Soyunda", $2+3+3+2+2+3$ dizilimiyle 8/8'lik ve 7/8'lik ölçülerin karmasından oluşmaktadır. (aynı dizilime sahip diğer iki türkü: "Acem Gızı" No:1398 ve "Martinim Atılmıyor" no:1747) Diğer ölçülerle birlikte yazılmış türküler ise, $3+2+2+3+2+3, \quad 2+2+2+2+3+2+2,2+2+2+2+2+3+2$ ve $2+2+3+3+2+3$ dizilimleriyle, $8 / 8,7 / 8$ ve 4/4' lük ölçü karmasından oluştuğu ve altı ya da yedi vuruşlu olduğu görülmektedir.
\end{abstract}

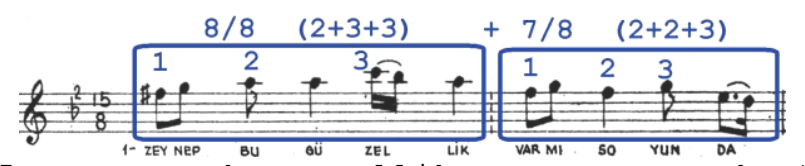

Örnek 5a. Zeynep bu güzellik var mi soyunda (Sivas)

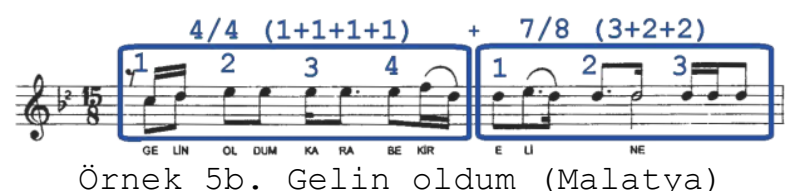

\title{
4.6. 16/8' Lik Ölçü (16/8 Measure)
}

TRT repertuvarında, 16/8'lik ölçüyle notaya alınmış beş, diğer ölçülerle birlikte notaya alınmış iki türkü bulunmaktadır. "Sallanı Sallanı Gelir" türküsü ve diğer iki türkünün aynı ölçü karması ve dizilime sahip olduğu belirlenmiştir. Tabloda yer alan diğer türküleri ise $2+3+3+3+3+2,2+2+3+2+2+2+3$ ve $3+2+2+2+3+2+2$, dizilimlerden oluştuğu görülmektedir. Ancak "Salına Salına Gelip" türküsü 3+2+3 diziliminin tekrarı olması nedeniyle 8/8'lik, "Ahmedim Handa" türküsü ise ölçü başına getirilecek sus ile $2+3+2+2$ dizilimiyle 9/8lik olarak yazılması daha uygun ve kolaylaştırıcı olacaktır. Tabloda yer alan türkülere bakıldığında, 16/8'lik ölçünün altı ya da yedi vuruşlu olarak kullanıldığı ve dizilimlerinin 8/8+8/8, 9/8+7/8, 7/8+9/8, 8/8+8/8 ve $7 / 8+9 / 8$ ölçü karmasından oluştuğu görülmektedir.

Tablo 6. 16/8'lik karma ölçü yapıları

(Table 6. $16 / 8$ mixed measure forms)

\begin{tabular}{|c|c|c|c|c|}
\hline Ölçü & Dizilim & Vuruş & Ölçü Karması & Türkünün Adı \\
\hline \multirow{3}{*}{$16 / 8$} & $3+2+3+3+2+3$ & 6 & $8 / 8+8 / 8$ & Sallanı Sallanı Gelir \\
\cline { 2 - 5 } & $2+2+3+2+2+2+3$ & 7 & $7 / 8+9 / 8$ & İstanbul'dan Gelir \\
\cline { 2 - 5 } & $3+2+2+2+3+2+2$ & 7 & $7 / 8+9 / 8$ & Ahmedim Handa \\
\hline
\end{tabular}

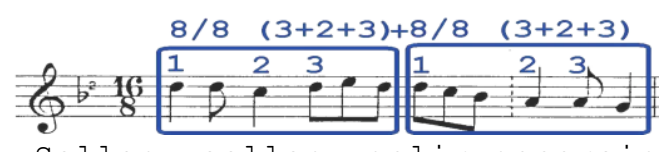

Örnek 6a. Sallanı sallanı gelir geçersin (Artvin)

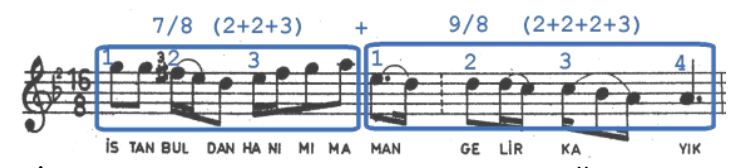

Örnek 6b. İstanbul'dan gelir kayık (Üsküdar-İstanbul)

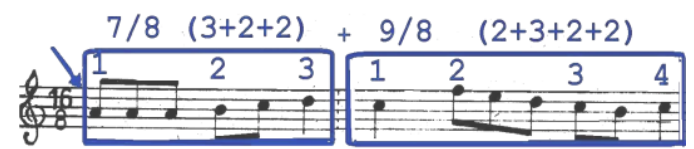

Örnek 6c. Ahmedim handadır (Balıkesir) 


\subsection{7/8' Lik Ölçü (17/8 Measure)}

Aşağıda tabloda görüldüğü gibi, TRT repertuarında 17/8'lik ölçüyle ve diğer ölçülerle birlikte notaya alınmış birer türkü bulunmaktadır. Malatya yöresine ait "Sabah Olur Oğlan Gider İşine" türküsü yedi vuruşlu, 2+2+2+3+3+2+3 diziliminde, 9/8+8/8'lik ölçü karmasından oluşmaktadır.

Tablo 7. 17/8'lik karma ölçü yapısı

(Table 7. $17 / 8$ mixed measure form)

\begin{tabular}{|c|c|c|c|c|}
\hline Ölçü & Dizilim & Vuruş & Ölçü Karması & Türkünün adı \\
\hline $17 / 8$ & $2+2+2+3+3+2+3$ & 7 & $9 / 8+8 / 8$ & Sabah Olur Oğlan \\
\hline
\end{tabular}

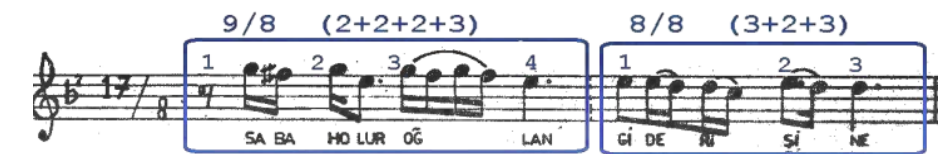

Örnek 7a. Sabah Olur oğlan gider işine (Malatya)

\subsection{8/8' Lik Ölçü (18/8 Measure)}

18/8'lik ölçünün hem bileşik hem de karma ölçü olarak kullanıldığı belirlenmiştir. Ancak, karma ölçü olarak az sayıda örneğe rastlanılmıştır. TRT Repertuarında 18/8'lik ölçüyle notaya alınmış 35 türkü bulunmaktadır. Bunlardan dört türkü karma diğerleri ise bileşik ölçü yapısındadır.

Tablo 8. 18/8'lik karma ölçü yapıları

(Table 8. $18 / 8$ mixed measure forms)

\begin{tabular}{|c|c|c|c|c|}
\hline Ölçü & Dizilim & Vuruş & Ölçü Karması & Türkünün Adı \\
\hline \multirow{4}{*}{$18 / 8$} & $3+2+3+3+2+2+3$ & 7 & $8 / 8+10 / 8$ & Uzunda Kavak \\
\cline { 2 - 5 } & $3+2+3+3+2+2+3$ & 7 & $8 / 8+10 / 8$ & Yar Oturmuş Dağ... \\
\cline { 2 - 5 } & $3+2+2+2+3+2+2+2$ & 8 & $9 / 8+9 / 8$ & Üşüdüm Eminem \\
\cline { 2 - 5 } & $3+3+3+3+3+3$ & 6 & $6 / 8+6 / 8+6 / 8$ & Diğer Türküler \\
\hline
\end{tabular}

Tablo 8'de yer alan iki türkü yedi vuruşlu, 8/8+10/8'lik ölçünün karması ve $2+3+3+2+3+2+3,3+2+3+3+2+2+3$ dizilimlerinden oluşmaktadır. "Üşüdüm Eminem" türküsü ise sekiz vuruşludur. Türkü $3+2+2+2+3+2+2+2$ diziliminde görüldüğü gibi iki 9/8'lik den oluşmaktadır. Bu nedenle türkünün aksak 9/8'lik olarak yazılması daha uygun olacaktır. Diğer türküler incelendiğinde ise genellikle bileşik ölçü yapısına sahip oldukları ve bu nedenle çoğunluğunun 6/8'lik olarak yazılması daha uygun ve daha gerçekçi olacaktır.

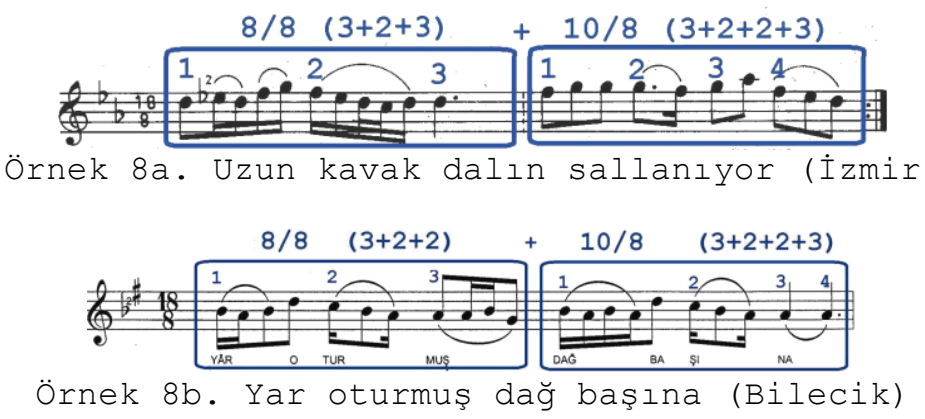

\subsection{9/8' Lik Ölçü (19/8 Measure)}

TRT repertuarında, 19/8'lik ölçüyle ve diğer ölçülerle birlikte notaya alınmış birer türkü bulunmaktadır. Tablo g'da görüldüğü gibi "Şarkışla İçinde" adlı türkü yedi vuruşlu, 2+3+3+3+3+2+3 diziliminde ve $5 / 8+9 / 8+5 / 8$ 'lik ölçü karmasından oluşmaktadır 
Tablo 9. 19/8'lik karma ölçü yapısı

(Table 9. $19 / 8$ mixed measure form)

\begin{tabular}{|c|c|c|c|c|}
\hline Ölçü & Dizilim & Vuruş & Ölçü Karması & Türkünün Adı \\
\hline $19 / 8$ & $2+3+3+3+3+2+3$ & 7 & $5 / 8+9 / 8+5 / 8$ & Şarkışla İçinde \\
\hline
\end{tabular}

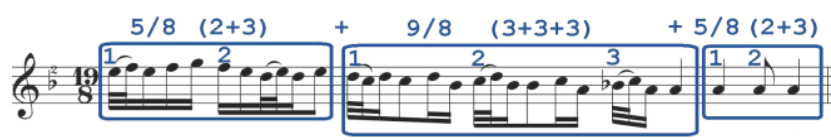

Örnek 9a. Şarkışla İçinde (Sivas)

\subsection{0/8' Lik Ölçü (20/8 Measure)}

TRT repertuarında $20 / 8^{\prime} l i k$ ölçüyle notaya alınmış dört ve diğer ölçülerle notaya alınmış dört türkü bulunmaktadır.

Tablo 10. 20/8'lik karma ölçü yapıları

(Table 10. 20/8 mixed measure forms)

\begin{tabular}{|c|c|c|c|c|}
\hline Ölçü & Dizilim & Vuruş & Ölçü Karması & Türkünün Adı \\
\hline \multirow{4}{*}{$20 / 8$} & $2+3+3+2+2+3+2+3$ & 8 & $5+8+10 / 8+5 / 8$ & Kar Yağar Bardan... \\
\cline { 2 - 5 } & $2+3+2+3+3+2+2+3$ & 8 & $5+8+5 / 8+10 / 8$ & Gedikte Duvak Allanır \\
\cline { 2 - 5 } & $3+2+2+3+3+2+2+3$ & 8 & $10 / 8+10 / 8$ & Pınar Başında Durma \\
\cline { 2 - 5 } & $2+3+3+2+2+3+3+2$ & 8 & $10 / 8+10 / 8$ & Çift Beyaz Güvercin \\
\hline
\end{tabular}

Tablo 10'da görüldüğü gibi 20/8'lik ölçüyle notaya alınmış türküler, 5/8'lik ya da 10/8'lik tabanll olarak $2+3+3+2+2+3+2+3$, $2+3+2+3+3+2+2+3, \quad 3+2+2+3+3+2+2+3, \quad 2+3+3+2+2+3+3+2 \quad$ dizilimleriyle yapılandığı görülmektedir. 5+8+10/8+5/8, 5+8+5/8+10/8, 10/8+10/8 gibi $5 / 8^{\prime} l i k$ ölçü ve katlarının farklı 2+3-3+2 konumlanmasından oluşmaktadır. Bu duruma paralel olarak "Kar Yağar Bardan Bardan" ve "Gedikte Duvak Allanır" türkülerinin 2+3 dizilimiyle5/8'lik, "Pınar Başında Durma" ve "Çift Beyaz Güvercin" türkülerinin ise 10/8'lik ölçüyle yazılması daha uygun olacaktır.

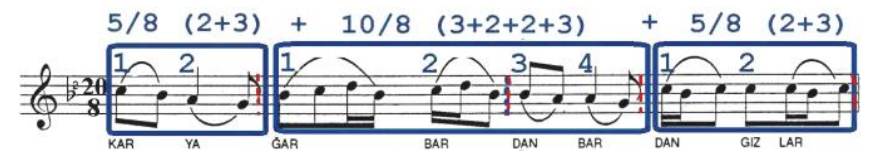

Örnek 10a. Kar yağar bardan bardan (Erzurum)

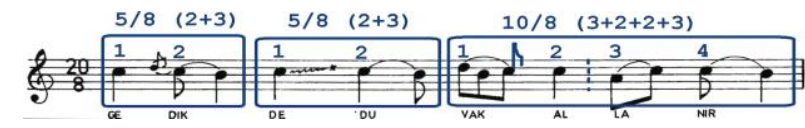

Örnek 10b. Gedikte duvak allanır (Erzurum)

\subsection{1/8' Lik Ölçü (21/8 Measure)}

TRT Repertuarında 21/8'lik ölçüyle notaya alınmış dört türkü bulunmaktadır. Tablo $11^{\prime}$ de yer alan üç türkü yedi, biri dokuz vuruşludur. Türküler $12 / 8+9 / 8,9 / 8+6 / 8+6 / 8,6 / 8+6 / 8+9 / 8,5 / 4+9 / 8{ }^{\prime} l i k$ ölçü karması ve $3+3+3+3+3+3+3, \quad 2+2+2+2+2+2+3+2+2$, dizilimlerinden oluşmaktadır. 21/8'lik ölçü üçerli dizilim biçimiyle bileşik ölçü yapısına sahip olduğu görülmektedir. Aşağıda nota örneği verilen ve bileşik ölçü yapısına sahip olan "Çimenli Bahçede" türküsü, yedinci vuruşa bir noktalı dörtlük eklenerek 12/8'lik olarak yazılması, "Giresun'dan Çıktım saat Beşidi" türküsünün ise 4/4 lük olarak düzeltilmesi daha uygun olacaktır. 


\begin{tabular}{l}
\hline \hline \multicolumn{5}{c|}{ Tablo 11. $21 / 8^{\prime}$ lik karma ölçü yapıları } \\
(Table 11. $21 / 8$ mixed measure forms) \\
\begin{tabular}{|c|c|c|c|c|}
\hline Ölçü & Dizilim & Vuruş & Ölçü Karması & Türkünün Adı \\
\hline \multirow{2}{*}{$21 / 8$} & $3+3+3+3+3+3+3$ & 7 & $12 / 8+9 / 8+12 / 8$ & Çimenli Bahçede \\
\cline { 2 - 6 } & $2+2+2+2+2+2+3+2+2$ & 9 & $5 / 4+9 / 8$ & Giresun' dan Çıktım \\
\hline
\end{tabular}
\end{tabular}
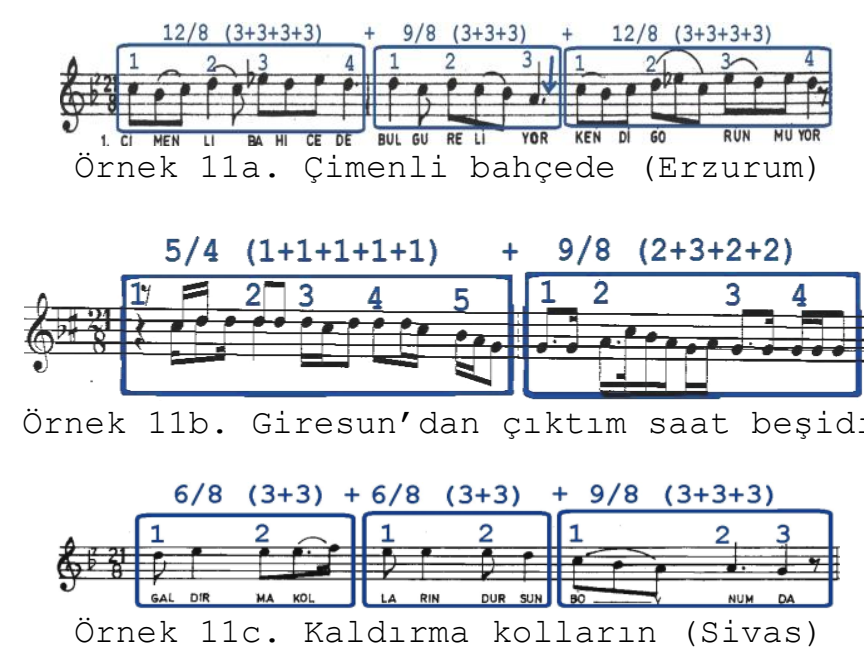

\subsection{3/8' Lik ölçü $(23 / 8)$}

TRT Repertuarında 23/8'lik ölçüyle notaya alınmış bir türkü bulunmaktadır. Tablo 12'de görüldüğü gibi "Bir Yiğit Gurbete Gitse" türküsü 11 vuruşlu, $1+1+1+1+1+1+3+2+2+1+1$ diziliminde ve $4 / 4+2 / 4+7 / 8+2 / 4$ ölçü karmasından oluşmaktadır. Bu türkünün, yedinci vuruşa bir sekizlik sus eklenmesi, nota değerleri onaltılık yerine sekizlik nota birimleriyle yazılması ve 4/4'lük olarak notaya alınması daha uygun ve gerçekçi olacaktır.

Tablo 12. 23/8'lik karma ölçü yapısı

(Table 12. $23 / 8$ mixed measure form)

\begin{tabular}{|l|c|c|c|c|}
\hline Ölçü & Dizilim & Vuruş & Ölçü Karması & Türkünün Adı \\
\hline $23 / 8$ & $1+1+1+1+1+1+3+2+2+1+1$ & 11 & $4 / 4+2 / 4+7 / 8+2 / 4$ & Bir Yiğit Gurbete \\
\hline
\end{tabular}

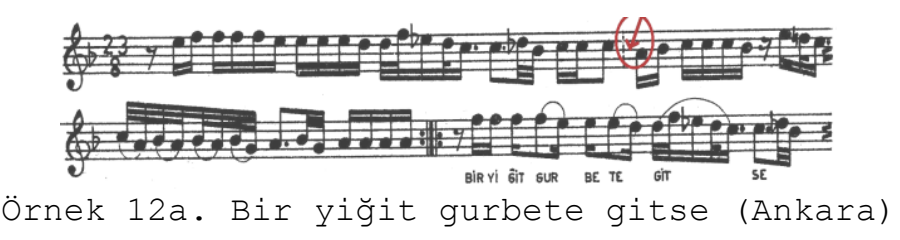

\subsection{3. $25 / 8^{\prime}$ Lik ölçü $(25 / 8$ Measure $)$}

TRT repertuarında, $25 / 8^{\prime} l i k$ ölçüyle notaya alınmış türkü bulunmamaktadır. Saz bölümü 25/8, söz bölümü 25/8'lik olan bir türkü bulunmaktadır. Tablo 13'de görüldüğü gibi "Üç Kuşuduk Uçar İdik Havada" adlı türkü on bir vuruşlu, $2+2+3+2+2+2+3+2+2+2+3$ diziliminde ve $7 / 8+9 / 8+9 / 8$ 'lik ölçü karmasından oluşmaktadır.

Tablo 13. 25/8'lik karma ölçü yapısı

(Table 13. $25 / 8$ mixed measure form)

\begin{tabular}{|c|c|c|c|c|}
\hline Ölçü & Dizilim & Vuruş & Ölçü Karması & Türkünün Adı \\
\hline $25 / 8$ & $2+2+3+2+2+2+3+2+2+2+3$ & 11 & $7 / 8+9 / 8+9 / 8$ & Üç Kuşuduk Uçar \\
\hline
\end{tabular}




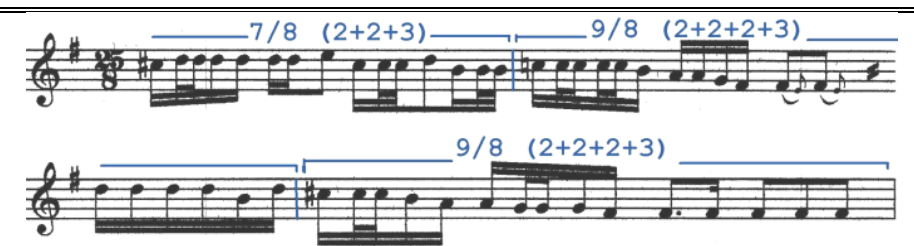

Örnek 13a. Üç kuşuduk uçar idik havada (Kastamonu)

"Üç Kuşuduk Uçar idik Havada" türküsünü notaya alan müzikolog Süleyman Şenel yapılan görüşmede "Kaynak kişi Yorgansız Hakkı Çavuş'un ritim duygusunun oldukça iyi olduğunu belirtmiş, bu nedenle söylemeden kaynaklanan bir ritim kusuru olmadığını, söz genişlemesinden kaynaklanan ritim genişlemeleri olduğunu, bu nedenle 25/8'lik ölçüyle notaya aldığını" belirtmiştir.

\subsection{7/8' Lik Ölçü (27/8 Measure)}

TRT Repertuvarında 27/8'lik ölçüyle notaya alınmış iki türkü bulunmaktadır. Tablo 14'de yer alan türkülerden "Yasemen Dalına" $3+2+2+2+3+2+2+2+3+2+2+2$ diziliminde ve "Şu Yüce dağların" türküsü ise $2+3+2+2+2+3+2+2+2+3+2+2$ dizilim biçimiyle notaya alındığı belirlenmiştir. Her iki türkü de on iki vuruşlu ve $9 / 8+9 / 8+9 / 8$ ölçü karmasından oluşmaktadır. Ancak, ölçünün uzun olması okuma zorluğu getireceği için; "Yasemen Dalına Yar Neden Eymeli" türküsü 3+2+2+2 dizilim biçimiyle, "Şu Yüce dağların Karı" türküsü ise 2+3+2+2 dizilim biçimiyle 9/8'lik olarak yazılması daha kolaylaştırıcı olacaktır.

Tablo 14. 27/8'lik karma ölçü yapıları

(Table 14. 27/8 mixed measure forms)

\begin{tabular}{|c|c|c|c|c|}
\hline Ölçü & Dizilim & Vuruş & Ölçü Karması & Türkünün Adı \\
\hline \multirow{2}{*}{$27 / 8$} & $3+2+2+2+3+2+2+2+3+2+2+2$ & 12 & $9 / 8+9 / 8+9 / 8$ & Yasemen Dalına \\
\cline { 2 - 5 } & $2+3+2+2+2+3+2+2+2+3+2+2$ & 12 & $9 / 8+9 / 8+9 / 8$ & Şu Yüce dağların \\
\hline
\end{tabular}
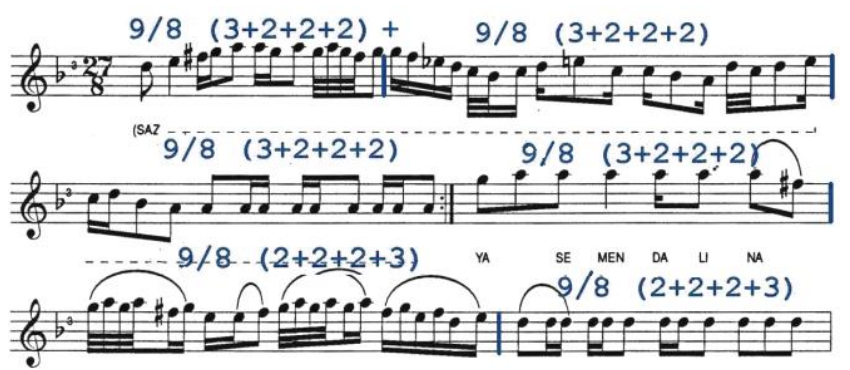

Örnek 14a. Yasemen dalına yar neden eymeli (Kütahya)

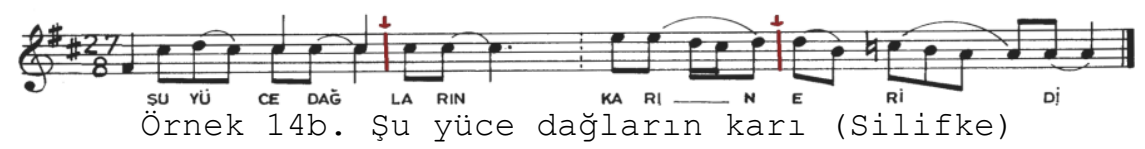

4.15. 28/8' Lik Ölçü (28/8 Measure)

TRT repertuarında, 28/8'lik ölçüyle notaya alınmış türkü belirlenememiştir. Diğer ölçülerle yazılmış bir türkü bulunmaktadır.

Tablo 15. 28/8'lik karma ölçü yapısı

(Table 15. $28 / 8$ mixed measure form)

\begin{tabular}{|c|c|c|c|c|}
\hline Ölçü & Dizilim & Vuruş & Ölçü Karması & Türkünün Adı \\
\hline $28 / 8$ & $3+2+3+2+3+2+3+2+3+2+3$ & $1 \mathrm{p} 1$ & $8 / 8+5 / 8+5 / 8+5 / 8+5 / 8$ & Ölüm $\dot{I} l e \ldots$ \\
\hline
\end{tabular}


Tablo 15'de görüldüğü gibi "Ölüm i̇le Ayrılık" adlı türkü on bir vuruşlu, $3+2+3+2+3+2+3+2+3+2+3$ diziliminde ve $8 / 8+5 / 8+5 / 8+5 / 8+5 / 8$ ' lik ölçü karmasından oluşmaktadır. Erzurum ve Kars yöresinde yaygın olarak kullanılan 5/8'lik ölçünün, hatalı ya da eksik çalma gibi nedenlerle karma ölçü olarak ölçülendirilmesi, 20/8, 28/8 ve 30/8'lik olarak notaya alınmış türkülerde fark edilmektedir. Bu açıdan bakıldığında, tablo 15'de yer alan türkünün de birinci ve ikinci cümle başına eklenecek bir vuruşluk sus ile 5/8'lik yazılması daha gerçekçi olacaktır.

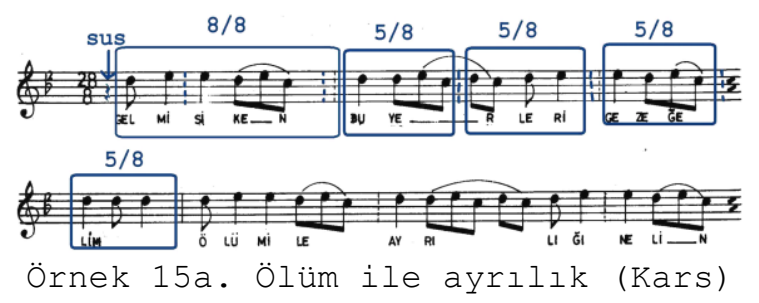

\subsection{0/8'Lik ölçü (30/8 Measure)}

TRT Repertuarında 30/8'lik ölçüyle notaya alınmış bir türkü bulunmaktadır. Tablo 16'da görüldüğü gibi "Hayal Hayal Olmuş" Karşıki Dağlar" adlı türkü on iki vuruşlu, $2+3+2+3+2+3+2+3+2+3+2+3$ diziliminde ve 5/8+5/8+7/8+8/8+5/8'lik ölçü karmasından oluşmaktadır. Sözlere göre ölçülendirme yapılan bu türkünün 5/8'lik olarak yazılması daha uygun olacaktır.

Tablo 16. 30/8'lik karma ölçü yapısı

(Table 16. $30 / 8$ mixed measure form)

\begin{tabular}{|c|c|c|c|c|}
\hline Ölçü & Dizilim & Vuruş & Ölçü Karması & Türkünün Adı \\
\hline $30 / 8$ & & 12 & $5 / 8+5 / 8+7 / 8+8 / 8+5 / 8$ & Hayal Hayal olmuş Karşıki Dağlar \\
\hline
\end{tabular}

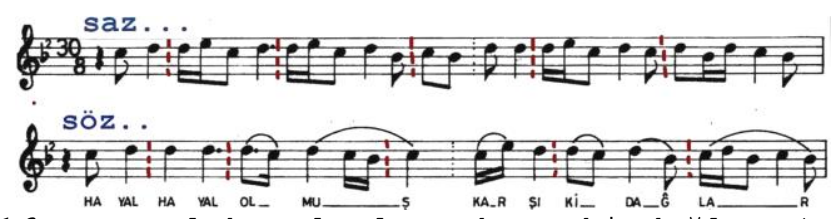

Örnek 16a. Hayal hayal olmuş karşı ki dağlar (Erzurum)

\section{SONUÇ VE ÖNERILER (CONCLUSION AND RECOMMENDATIONS)}

Bu araştırmada incelenen karma ölçü olarak notaya alınmış türküler şu şekilde yer almıştır (EK 2).

TRT Repertuarında; 11/8'lik beş, diğer (örn.11/8+4/4) sekiz, 12/8'lik iki, diğer bir, 13/8 dört, diğer altı, 14/8'lik üç, diğer üç, 15/8'lik beş, diğer iki, 16/8'lik beş diğer iki, 17/8'lik bir ve 18/8'lik ölçüyle notaya alınmış 35 türkü bulunmaktadır. 18/8'lik ölçüyle yazılmış dört türkü aksak, diğerleri ise bileşik ölçü yapısındadır. 19/8'lik bir, 20/8'lik dört, 21/8'lik dört, 23/8'lik bir, 25/8'lik bir, 27/8'lik iki, 28/8'lik bir ve 30/8'lik ölçüyle notaya alınmış bir türkü bulunduğu belirlenmiştir.

Yukarıda verilen ölçülerle notaya alınmış türkü sayısı, repertuvarda yer alan yaklaşık beş bin türkü içerisinde küçük bir kısmı oluşturmaktadır. Buna karşın, karma ölçülerin ritmik dizilimler açısından oldukça ilginç, renkli ve yaratıcı olduğu görülmektedir. Matematiksel olarak karma ölçülerin mümkün olduğu, ancak uygulamadaki zorlukları göz önüne alındığında, 19/8'lik ve üzeri notaya alınan ölçülerin kolaylaştırıcı anlayışla ele alınması ve yeniden ölçülendirilmesi daha doğru bir yaklaşım olacaktır. Bu açıdan karma ölçülerin, Geleneksel Türk halk müziği içerisinde yeri ile ilgili 
tartışmalara katkıda bulunmak ve daha gerçekçi bir değerlendirme yapmaya yönelik olarak:

- İncelenen türkülerin önemli bir kısmının, farklı dizilim, vuruş ve ölçü karmalarından oluştu, bir kısmının ise abartılı ya da çeşitli eksikliklerden kaynaklandığı belirlenmiştir.

- Kaynak kişinin türküyü ölçü, tartım ve ezgisel olarak yanlış ya da eksik seslendirmesi nedeniyle, notaya alanın ölçüyü tam olarak belirleyemediği,

- Bazı türkülerin ölçü başına dörtlük ya da sekizlik bir sus eklenmesiyle, türkünün daha doğru bir şekilde ölçülendirmesinin mümkün olacă̆ı,

- Bazı türkülerin, "yazılması daha uygun" ölçüde yazılmadığı, bu nedenle 16/8'lik ölçünün 8/8'lik, 18/8'lik ölçünün 6/8'lik ya da 9/8lik, 20/8'lik ölçünün 5/8'lik, 27/8'lik ölçünün ise 9/8'lik ölçüyle yazılmansın daha uygun ve kolaylaştırıcı olacağı,

- Karma ölçü olarak yazılan bazı türkülerin, sözler temel alınarak ölçülendirildiği izlenimi oluştuğu, "Hayal Hayal Olmuş Karşıki Dağlar" türküsünde olduğu gibi, bu durumun ölçülendirmeyi karışık hale getirdiği,

- Karma ölçülerin, TRT repertuarında sadece sözlü türküler kısmında bulunması, çoğunlukla türkü sözlerine göre belirlendiği ve sözsüz ezgilerde kullanılmadığı sonucuna ulaşılmıştır.

- Bu araştırmada yer alan 11/8 ve 15/8'lik arasında bulunan ölçülerin gerçekçi,16/8 ve 18/8'lik arasında bulunan ölçülerin mümkün, 19/8'lik ve üstü ölçülerin abartılı ve gerçekçi olmadığı izlenimi oluşmaktadır. verilmiştir.

Araştırmadan elde edilen sonuçlara göre aşağıdaki öneriler

- TRT repertuarında karma ölçü olarak notaya alınmış türküler, ezgi ve ölçülendirme açısından yeniden gözden geçirilmelidir.

- Karma ölçüler, vücut perküsyonu eğitimcileri, vurmalı çalgı çalıcıları, besteciler ve özellikle film müziği bestecileri için esin kaynağı oluşturacak ritimsel bir zenginlik içerdiği göz önünde alınmalıdır.

- Türkü notaya alanların, türkünün ölçüsünü belirlerken titiz davranmaları ve ölçüsünden emin olmadıkları türküleri mümkünse farklı kaynaklardan doğrulamaları önerilmektedir.

- Geleneksel Türk halk müziği eğitimcileri ölçü ya da usul eğitimi verirken, karma ölçülere de yeteri kadar yer vermelidir.

\section{KAYNAKLAR (REFERENCES)}

- Akbıyık, S., (Kasım 2016-Mart 2017). Repertuvar Türküleri Külliyatı http://www.repertukul.com/.

- Emnalar, A., (1998). Türk Halk Müziği ve Nazariyatı. İzmir: Ege Üniversitesi Basımevi

- Büyükyıldız, Z., (2009). Türk Halk Müziği-Ulusal Türk Müziği. İstanbul: Papatya Yayıncılık.

- Karp, T., (1997). Dictionary of Music. Northwstern University Pres Evanston USA.

- Kaymak, M., (1982). Türk Halk Müziği ve Oyunları Sayı:4 Ankara: G. Ü. Basın Yayın Basın Yayın Yüksekokulu Basımevi.

- Ashish, P., (2005). Encyclopaedic Dictionary of Music. New Delhi: İsha Books

- Özkan, T., (1989). Türk Halk Müziğinin Makam ve Usul Yapısının Analizi. (Analyse des mesures (rythmes) et des modes de la 
musique populaire turque) Yayımlanmamış Müzikoloji Doktora Tezi Paris. Université (Sciences humaines et sociales-Arts-LettresDroit.

- Ursala Reinhard, K., (2007). Türkiye'nin Müziği. Cilt:2 Sun Yayınları, Ankara.

- Sarısözen, M., (1962). Türk Halk Musikisi Usulleri. Ankara:Resimli Posta Matbaası.

- Şenol, A., (2016). Geleneksel Türk Halk Müziğinde Kullanılan Aksak Ölçülü Türkülerin Flüt Eğitiminde Karşılaşılan Zorluklarının İncelenmesi. Yayımlanmamış Doktora Tezi. Ankara: Gazi Üniversitesi Eğitim Bilimleri Enstitüsü.

- Terzi, C., (1992). Türk Halk Müziği Metrik Yapısının Tespit ve Tasnifinde Karşılaşılan Problemler ve Çözüm Yolları.

Yayımlanmamış Sanatta Yeterlik Tezi. İstanbul: İstanbul Teknik Üniversitesi Sosyal Bilimler Enstitüsü.

- TRT, (2009). Türk Halk Müziği Sözlü Eserler Antolojisi Cilt-1, 2 Akara: TRT Yayınları.

\section{EK 1 (ADDITIONAL 1)}

TRT "Sözlü Türküler" Repertuvarında 4989 türkü içerisinde belirlenen, karma ölçü ve diğer ölçülerle birlikte yazılmış türkülerin dağılımı (Akbıyık 2017).

\begin{tabular}{|c|c|c|c|}
\hline Ölçü & Notaya Alınan & Diğer Ölçülerle & Toplam \\
\hline $11 / 8$ & 5 & 8 & 13 \\
\hline $12 / 8$ & 2 & 1 & 3 \\
\hline $13 / 8$ & 4 & 6 & 10 \\
\hline $14 / 8$ & 3 & 3 & 6 \\
\hline $15 / 8$ & 5 & 2 & 7 \\
\hline $16 / 8$ & 5 & 2 & 7 \\
\hline $17 / 8$ & 1 & 1 & 2 \\
\hline $18 / 8$ & 4 & 2 & 6 \\
\hline $19 / 8$ & 1 & 1 & 2 \\
\hline $20 / 8$ & 4 & 4 & 8 \\
\hline $21 / 8$ & 4 & - & 1 \\
\hline $23 / 8$ & 1 & - & 1 \\
\hline $25 / 8$ & - & 1 & 2 \\
\hline $27 / 8$ & 2 & - & 1 \\
\hline $28 / 8$ & - & 1 & 1 \\
\hline $30 / 8$ & 1 & - & 32 \\
\hline Toplam & 42 & & \\
\hline
\end{tabular}

Tabloda yer alan 12/8'lik ve 18/8'lik ölçü içerisine bileşik ölçü olarak yazılmış türküler alınmamış, sadece karma ölçü olarak notaya alınmış türküler gösterilmiştir. 
Tuğcular, E.

Fine Arts (NWSAFA), D0196, 2017; 12(2): 149-163. künyesi.

EK 2 (ADDITIONAL 2)

$\mathrm{Bu}$ araştırmada İncelenen türkülerin yapısal durumları ve

\begin{tabular}{|c|c|c|c|c|c|c|}
\hline & Dizilim & $\mathrm{V}$ & Ölçü Karması & Türkü Adı & Derleyen & R. No \\
\hline \multirow{5}{*}{$11 / 8$} & $2+2+3+2+2$ & 5 & $7 / 8+2 / 4$ & Başı Pare Pare & O.Özdenkçi & 0658 \\
\hline & $3+2+2+2+3$ & 5 & $5 / 8+7 / 8$ & Gül Kuruttum & M.Srısöze & 0664 \\
\hline & $3+2+3+3$ & 4 & $5 / 8+6 / 8$ & Havada Kar Sesi & M.Srısözen & 653 \\
\hline & $2+3+3+3$ & 4 & $5 / 8+6 / 8$ & Top Yatağın Önü & E.Aldemir & 1510 \\
\hline & $3+3+3+2$ & 4 & $6 / 8+5 / 8$ & Güzel Yanlış & T.Şan & 1864 \\
\hline \multirow{2}{*}{$12 / 8$} & $2+3+3+2+2$ & 5 & $8 / 8+2+4$ & İndim Koç Babayı & N.Tüfekçi & 1044 \\
\hline & $3+2+2+2+3$ & 5 & $5 / 8+7 / 8$ & Tutam Yar Elinden & C.Demirsi & 0665 \\
\hline \multirow{4}{*}{$13 / 8$} & $3+3+2+2+3$ & 5 & $6 / 8+7 / 8$ & Selam Olsun & M.Çalmaşır & 3241 \\
\hline & $2+3+3+2+3$ & 5 & $8 / 8+5 / 8$ & Yeni Kapının Gelini & N.Kaya & 4393 \\
\hline & $2+3+1+1+1+1$ & 6 & $5 / 8+4 / 4$ & Gelin Çıkarma & N.Berbergil & 3371 \\
\hline & $2+2+2+2+3+2$ & 6 & $4 / 4+5 / 8$ & Ahmedim & İ.Can & 4808 \\
\hline \multirow{5}{*}{$14 / 8$} & $3+2+3+3+3$ & 5 & $8 / 8+6 / 8$ & Fincanın İçi & D.Yazıcıо.. & 1126 \\
\hline & $3+3+3+3+2$ & 5 & $9 / 8+5 / 8$ & Çattılar Ocak & N.Tüfekçi & 1477 \\
\hline & $3+3+3+2+3$ & 5 & $6 / 8+8 / 8$ & İndim Yarin & N.Kaya & 3284 \\
\hline & $2+2+2+3+2+3$ & 6 & $9 / 8+5 / 8$ & Yollar Seni Gide & M.Seske & 3021 \\
\hline & $3+2+2+2+3+2$ & 6 & $7 / 8+8 / 8$ & Bir Yar Getirmişim & M.Özbek & 1949 \\
\hline \multirow{5}{*}{$15 / 8$} & $2+3+3+2+2+3$ & 6 & $8 / 8+7 / 8$ & Zeynep Bu Güzellik & M.Srısözen & 0331 \\
\hline & $2+2+3+3+2+3$ & 6 & $7 / 8+8 / 8$ & Uyan Gözlerine & R.Kartal & 2212 \\
\hline & $2+3+3+2+2+3$ & 6 & $8 / 8+7 / 8$ & Evleri Fadimelim & N.Akben & 2805 \\
\hline & $3+2+2+3+2+3$ & 6 & $7 / 8+8 / 8$ & Yeşil İpek & T.Büykkaya & 3974 \\
\hline & $2+2+2+2+3+2+2$ & 7 & $4 / 4+7 / 8$ & Gelin Oldum & U.Erbaş & 4205 \\
\hline \multirow{3}{*}{$16 / 8$} & $3+2+3+3+2+3$ & 6 & $8 / 8+8 / 8$ & Salına Salına & D.Yazıcıoğlu & 0126 \\
\hline & $2+2+3+2+2+2+3$ & 7 & $9 / 8+7 / 8$ & İstanbul'dan Gelir & M.Srısözen & 0670 \\
\hline & $3+2+2+2+3+2+2$ & 7 & $7 / 8+9 / 8$ & Ahmedim Handadır & N.Çamlıdağ & 2080 \\
\hline $17 / 8$ & $2+2+2+3+3+2+3$ & 7 & $9 / 8+8 / 8$ & Sabah Olur Oğlan & M.Özbek & 2074 \\
\hline \multirow{3}{*}{$18 / 8$} & $3+2+3+3+2+2+3$ & 7 & $8 / 8+10 / 8$ & Uzunda Kavak & E.Güver & 1857 \\
\hline & $3+2+3+3+2+2+3$ & 7 & $8 / 8+10 / 8$ & Yar Oturmuş Dağ.. & S.Y.Bircan & 4526 \\
\hline & $\begin{array}{c}3+2+2+2+3+2+2+ \\
2 \\
\end{array}$ & 8 & $9 / 8+9 / 8$ & Üşüdüm Eminem & H.Karakaş & 4079 \\
\hline $19 / 8$ & $2+3+3+3+3+2+3$ & 7 & $5 / 8+9 / 8+5 / 8$ & Şarkışla İçinde & İ.Öztürk & 4959 \\
\hline \multirow{4}{*}{$20 / 8$} & $\begin{array}{c}2+3+3+2+2+3+2+ \\
3\end{array}$ & 8 & $5+8+10 / 8+5 / 8$ & Kar Yağar Bar.. & N.Tüfekçi & 0006 \\
\hline & $\begin{array}{c}2+3+2+3+3+2+2+ \\
3 \\
\end{array}$ & 8 & $5+8+5 / 8+10 / 8$ & Gedikte Duvak Alla. & M. Günaydın & 1222 \\
\hline & $\begin{array}{c}3+2+2+3+3+2+2+ \\
3\end{array}$ & 8 & $10 / 8+10 / 8$ & Pınar Başında Durma & M. Günaydın & 1227 \\
\hline & $\begin{array}{c}2+3+3+2+2+3+3+ \\
2 \\
\end{array}$ & 8 & $10 / 8+10 / 8$ & Çift Beyaz Güvercin & N.Tüfekçi & 1314 \\
\hline \multirow[b]{2}{*}{$21 / 8$} & $3+3+3+3+3+3+3$ & 7 & $12 / 8+9+8$ & Çimenli Bahçede & M.Srısözen & 0531 \\
\hline & $\begin{array}{c}2+2+2+2+2+2+3+ \\
2+2+2+2\end{array}$ & 11 & $\begin{array}{c}4 / 4+2 / 4+7 / 8+ \\
2 / 4 \\
\end{array}$ & Bir Yiğit Gurbete & S.Özbilen & 0647 \\
\hline $23 / 8$ & $\begin{array}{c}2+2+3+2+2+2+3+ \\
2+2+2+3\end{array}$ & 11 & $7 / 8+9 / 8+9 / 8$ & Üç Kuşuduk Uçar & S.Şenel & 3468 \\
\hline $25 / 8$ & $\begin{array}{c}3+2+2+2+3+2+2+ \\
2+3+2+2+2\end{array}$ & 12 & $9 / 8+9 / 8+9 / 8$ & Yasemen Dalına & N.Tüfekçi & 0048 \\
\hline \multirow{2}{*}{$27 / 8$} & $\begin{array}{c}2+3+2+2+2+3+2+ \\
2+2+3+2+2\end{array}$ & 12 & $9 / 8+9 / 8+9 / 8$ & Şu Yüce dağların & N.Tüfekçi & 1467 \\
\hline & $\begin{array}{c}3+2+3+2+3+2+3+ \\
2+3+2+3\end{array}$ & 11 & $\begin{array}{c}8 / 8+5 / 8+5 / 8+ \\
5 / 8+5 / 8\end{array}$ & Ölüm İle Ayrılık & N.Tüfekçi & 1791 \\
\hline $28 / 8$ & $\begin{array}{c}2+3+2+3+2+3+2+ \\
3+2+3+2+3\end{array}$ & 12 & $\begin{array}{c}5 / 8+5 / 8+7 / 8+ \\
8 / 8+5 / 8 \\
\end{array}$ & Hayal Olmuş & İTÜ.Konsrv & 3529 \\
\hline $30 / 8$ & $\begin{array}{c}2+2+2+2+2+2+3+ \\
2+2+2+2\end{array}$ & 11 & $\begin{array}{c}4 / 4+2 / 4+7 / 8+ \\
2 / 4 \\
\end{array}$ & Bir Yiğit Gurbete & S.Özbilen & 0647 \\
\hline
\end{tabular}

